\title{
Do Species’ Abundances become More Spatially Variable with Stress?
}

\author{
J.E. Hewitt ${ }^{*}$ and S.F. Thrush ${ }^{*}$
}

National Institute of Water and Atmospheric Research, P.O. Box 11115 Hamilton, New Zealand

\begin{abstract}
The relationship between stress and population variability is essential for predicting whether communities will exhibit stability and resilience when faced with stress. Stress is generally considered to increase biological variability, even before mean responses exhibit change. However, generalities related to spatial variability of populations have not emerged, as large-scale perturbations tend to reduce variability in affected areas (i.e., a homogenising effect), and a positive relationship between mean and variance is expected at all scales. To investigate whether stress does increase the spatial variability of macrobenthic species abundances, we analysed the response of survey and experimental data, collected over a variety of space $(50 \mathrm{~m}$ to $5 \mathrm{~km})$ and time scales $(15 \mathrm{~d}$ to $15 \mathrm{yr})$, to two different stressors. We observed no consistent increase in variability as a response to stress, even within studies. Moreover, a complex relationship was observed between spatial variance and mean abundances that was not represented by a simple power law. However, one consistent response was observed across stressors and study type; the number of common species exhibiting changes (either increases or decreases) to their spatial variability, beyond natural levels, increased with stress. It seems likely that having species within a community whose spatial variability responds in different ways to stress (rather than spatial variability of all species increasing) may be crucial to smoothing out tensions between species and increasing resilience.
\end{abstract}

Keywords: Macrobenthos, variance-mean relationships, scale, coefficient of variation, standard deviation, organic enrichment, sedimentation.

\section{INTRODUCTION}

Variability in space and time is recognised important for the functioning of populations, communities and ecosystems (e.g., Legendre (1993) and references therein). Thus, changes to variability resulting from stress should have profound implications for biodiversity, stability and resilience. While studies on variability in response to stress encompass genetics, behaviour, and population and community ecology (Simkiss \& Mason 1984, Warwick \& Clarke 1993, Forbes et al. 1995, Callaghan \& Holloway 1999, Underwood \& Chapman 2004), and vary in scale, focus (space or time) and results, most consider stress to increase variability. However, for the spatial variability of population abundance there are two other theories concerning the effect of stress: at large spatial scales homogenisation is often predicted (Tilman et al. 1994, Crooks \& Sanjayan 2006); and a positive relationship should exist between mean and variance independent of environmental factors and scale (the power law sensu (Taylor 1961, Taylor et al. 1980)).

Increases in variability are suggested to be a sensitive response, occurring before gross changes in mean abundance. However, it is easy to develop scenarios where spatial variability in abundance may increase or decrease dependent on environmental factors, species interactions, or populationspecific spatial patterns (degree of aggregation, density). Moreover, spatial patterns resulting from biotic processes or resource requirements may change over an organism's life cycle (e.g., Taylor 1984, Elliott 2005), requiring changes in

*Address for correspondence to these authors at the National Institute of Water and Atmospheric Research, P.O. Box 11115 Hamilton, New Zealand; E-mail: j.hewitt@niwa.co.nz,s.thrush@niwa.co.nz

Handling editor: Prof. Malcolm S. Hill heterogeneity resulting from stress to be assessed against natural variability in heterogeneity (Inchausti \& Halley 2002).

A further problem in assessing the response of variability to stress is deciding what measure of variability to use. Gaston \& McArdle (1994) reported 23 measures of variability in the ecological literature with the three most common being the variance, the standard deviation (the positive square root of the variance) and the coefficient of variation (standard deviation divided by the mean). While these could show different responses to stress as a marked decrease in mean abundance may naturally cause the variance (and thus the standard deviation) to decrease as the coefficient of variation increases, this is considered unusual (Lewontin 1966, Gaston \& McArdle 1994). Consequently, understanding whether the relationship between the variance and the mean is affected by stress is critical. To date, studies have demonstrated both spatial consistency and inconsistency of the power law for individual species (Taylor 1971, Downing 1979, Certain et al. 2007), although the effect of anthropogenic stressors has not been considered.

This study investigates spatial variability in the abundance of a number of intertidal macrobenthic species under both natural and stressed conditions. We tested four predictions for natural conditions and three for stressed conditions. For natural conditions we predicted that spatial variability, at the scale of $10 \mathrm{~s} \mathrm{~ms}$, of a species could (N1) exhibit seasonal and multi-year cycles, and (N2) exhibit differences between sites at the scale of kms. We further predicted that (N3) natural changes in spatial variability over time at a site would not result in changes to the variance mean relationship (Fig. 1A), but that (N4) natural differences between sites in either species interactions or environmental conditions were likely to 


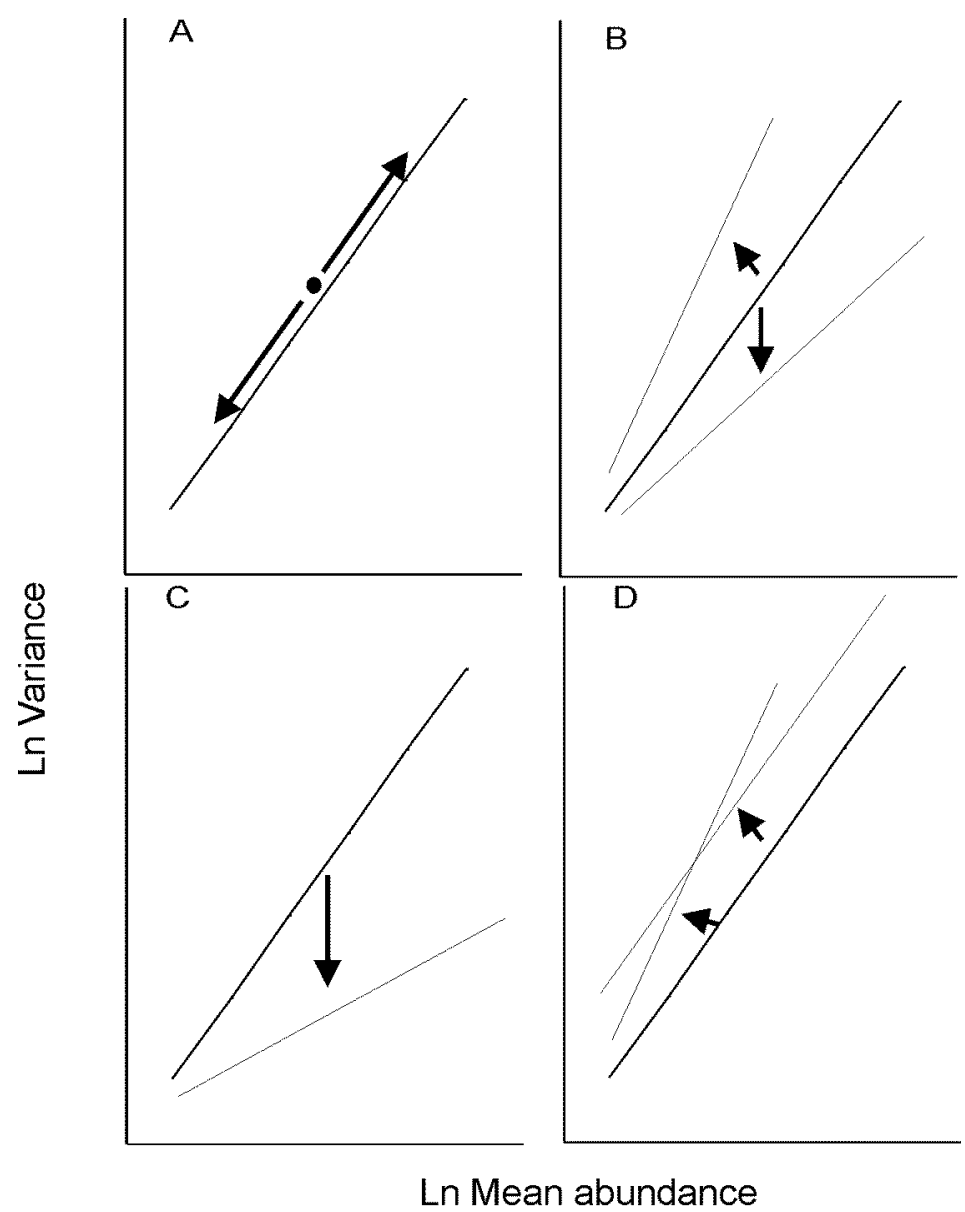

Fig. (1). Potential natural log variance-mean relationships. A, general relationship predicted to have slope of 2 (see Kilpatrick \& Ives (2003), natural changes at a site should move site position up or down this line. B. Differences in resources can result in differences in slopes at different sites (Krasnov et al. 2006 Elliott 2005). C, decreased slopes have been associated with increasing community diversity (Krasnov et al. 2006), carrying capacity (Keeling 2000), scale (Keeling 2000) and transient species (Magurran \& Henderson 2003). D, If stress increases variance both the slope or intercept could increase.

result in different variance-mean relationships for a species at different sites (Fig 1B, 1C). Under stressed conditions we predicted that (S1) spatial variability as represented by the $\mathrm{CV}$ will always increase (S2) the SD may decrease if the mean abundance decreases markedly. Furthermore we predicted that (S3) the effect of stress increasing spatial variability as indicated by the CV would be reflected in changes to the variance-mean relationship exhibited as increased slopes or intercepts (Fig. 1D).

\section{METHODS}

\section{General Details}

Data for the study came from the mid-low tide areas of three New Zealand harbours (Manukau, Mahurangi and Whitford Embayment). These areas are located in the Auckland region (North Island) and are separated by $\sim 30 \mathrm{~km}$. Manukau is the second largest harbour in New Zealand covering $\sim 350 \mathrm{~km}^{2}$ and opens to the Tasman Sea. Mahurangi and Whitford are smaller and open to the Pacific Ocean. Data from Manukau and Mahurangi were derived from longterm monitoring programs which sampled relatively homogenous sites of $\sim 1$ ha. In Manukau, the 6 sites sampled were $>88 \%$ sand. In Mahurangi, intertidal areas vary mark- edly in sediment type and the 5 sites sampled varied from being muddy silt to predominantly sand. Data from Whitford were from 2 experiments conducted at sandy sites over a 250 $\mathrm{m}^{2}$ area with manipulations conducted inside $1 \mathrm{~m}$ diam. plots.

All data were collected by $13 \mathrm{~cm}$ diam., $15 \mathrm{~cm}$ deep cores sieved on a $0.5 \mathrm{~mm}$ mesh. Individuals were identified to the lowest practical taxonomic level and counted. The species data from each site at each location was analysed to produce a list of abundant species (average $>2$ individuals per core). These species represented a number of different orders, life history traits and seasonal patterns of abundance and a number of inter- and intra-specific interactions have been demonstrated for the species (Thrush et al. 1992, Thrush et al. 1996, Whitlatch et al. 1997, Thrush et al. 2006).

Responses of common macrofaunal species to low degrees of stress at a number of different spatial $(50 \mathrm{~m}$ to $5 \mathrm{~km})$ and temporal ( $15 \mathrm{~d}$ to $15 \mathrm{yr})$ scales were assessed. Two environmental changes that can stress benthic species were used: decreased supply of organic material to the sediments (sediment organic content of sediment decreased from $\sim 1.5 \%$ to $0.6 \%$ ); and changes in the muddiness of sediments (a gradient of 6 to $45 \%$ in sediment mud content). As the effects of these stressors were assessed using broad-scale survey data, 
the results of two manipulative experiments focused on increased sedimentation of terrestrial sediment were also investigated.

Both measures of heterogeneity used, the CV and the SD of the $\log _{\mathrm{e}}(\mathrm{x})$ abundance, are considered to be relatively unbiased measures (Gaston \& McArdle 1994) and should give similar results (Gaston \& McArdle 1994), especially when CV is $<30 \%$ (Lewontin 1966). This is particularly important as measured heterogeneity could become higher when abundances are low as sampling efficiency decreases. As we were interested in variation of animals at a site we included zero counts thus the standard deviation of the $\log _{\mathrm{e}}(\mathrm{x}+1)$ was used (see also McArdle \& Gaston 1993, Heath 2006).

Note that generally variance-mean relationships were developed on data where the range of abundance spanned at least 2 orders of magnitude (Taylor et al. 1988, Gaston \& McArdle 1994).

\section{Predictions N1-4: Natural Changes in Spatial Variability and the Variance-Mean Relationship Over Time and Space}

The data analysed to test these predictions came from the Manukau, where bi-monthly sampling, between October 1987 and February 1993, occurred at 6 sites spread throughout the harbour, separated by between $1-11 \mathrm{~km}$. Community dynamics were stable at all six sites over this time period (Turner et al 1995). Sampling at two of the sites continued and is ongoing. At these two sites community dynamics have continued to be stable (Hewitt pers. comm.).

All six sites were sized 9000 ha but varied in shape (100 x $90 \mathrm{~m}$ or $180 \times 50 \mathrm{~m}$ ) depending on the shape of the intertidal area. Each site was spatially stratified into 12 equal sized cells $(25 \times 30 \mathrm{~m})$, from each of which 1 replicate was taken (Hewitt \& Thrush 2007). This degree of spatial replication was sufficient to give precise estimates of the mean (Thrush et al. 1994) and thus good estimates of variance.

For testing hypothesis N1 (the presence of seasonal and annual changes) and $\mathrm{N} 3$ (natural changes in spatial variability over time would not result in changes to the variance mean relationship), all common species at a site were used, For testing N2 and N4 (differences between sites in CV, SD and variance-mean relationships), nine species that occurred in abundance at more than 1 site were used. The presence of seasonal and multi-year cycles in CV and SD for each common species was analysed graphically for each of the 6 sites. Longer-term changes in $\mathrm{CV}$ and SD were tested for at the two long-term monitored sites by using t-tests to compare two 5 yr periods (April 1988 - February 1993 and April 2000 - February 2005). Differences in the variance-mean relationship between these two time periods were determined by ANCOVA. Differences in CV and STD between the 6 sites were analysed by ANOVA with differences in the variance-mean relationship determined by ANCOVA.

\section{Predictions S1-3: Does Stress Increase Spatial Variability and the Slopes or Intercepts of the Variance-Mean Rela- tionship?}

The data for testing this prediction came from three locations (Manukau, Whitford and Mahurangi).
In the Manukau, at the start of sampling in 1987 one of the six sites $(\mathrm{CH})$ was located $7 \mathrm{~km}$ downstream from an oxidation pond discharge that had been in operation for over 20 years. The low level of enrichment which reached this site had not resulted in a depauperate community or even one that was markedly different from others in the harbour (Turner et al. 1995). Monitoring at this site was stopped after February 1993 and then restarted again in June 2000 as in April 2001 the discharge for the oxidation ponds was to be stopped. Small concomitant changes in water chlorophyll $a$, ammonium and nitrate concentrations were recorded near the site over the next 5 years (Wilcock \& Martin 2003). As this site had experienced a low level of enrichment for so many years, the chlorophyll a content of the sediment decreased post April 2001 and the community composition changed, its removal is treated in this study as a stressor for many species in the resident community. The two long-term monitoring sites in the Manukau were located well away from the sewage discharge and other sources of contamination, thus they serve as controls. CV and SD were calculated for all common species at the three sites (Table 1) on each sampling occasion and tested by t-tests for differences between the periods 1988-1993 and 2000-2005 (hypotheses S1 and S2). Differences in the slopes and intercepts of the variance mean relationship for each species at each site between the two periods were analysed by ANCOVA. Observed changes for species at the $\mathrm{CH}$ site were only assumed to be related to stress if mean abundance of the species did not show an increase and if similar changes did not occur at either of the 2 control sites. Furthermore, as some changes may occur by chance, the number of species exhibiting changes at $\mathrm{CH}$ was compared with the number of species exhibiting changes at the two control sites.

Data from Whitford sedimentation experiments were collected 15 days after the experimental addition of sediment at depths of $0,1,3,5$ and $7 \mathrm{~mm}$ at two sites which covered a 50 x $50 \mathrm{~m}$ area Lohrer et al. (2004). Each site had four replicates of each treatment level and two cores were collected within each treatment plot. An additional 8 cores were collected in ambient sediment around the site, giving 16 replicates for the 0 sediment addition treatment. CV and SD were calculated for common species/site on each sampling occasion in each treatment and then correlated with treatment (depth of sediment added), thus a significant positive relationship demonstrates an increase in variance with increased stress. The effect of sediment addition on the variance mean relationship was calculated by including a sediment depth interaction in the model for each site. A significant interaction meant that the slope of the variance mean relationship changed with stress (depth of sediment addition). The interactions terms were then analysed to determine whether slopes decreased or increased.

Data from the Mahurangi were collected quarterly between $1995-2001$, at 5 sites located along a gradient of sediment mud content. Spatial sampling at each site was the same as for sites in the Manukau. Species common at more than 2 sites were identified and categorised into those expected to prefer mud, avoid mud, prefer intermediate mud concentrations or unknown, based on summaries of experimental studies (Thrush et al. 2003, Thrush et al. 2004). Note that these summaries include the results of the sedimentation experiments conducted in Whitford. Species with unknown 
Table 1. Slope of the Variance-Mean Relationships Found at each Site for which a Species was Common. Results of an ANCOVA on Differences between Sites are Given as the Type 3 p-Value for Site and for the Interaction Term (AC*). Results of ANOVA Investigation of Differences between Sites in SD and CV are also Given. Significant Values are Indicated in Bold

\begin{tabular}{|c|c|c|c|c|c|c|c|c|c|c|}
\hline Aricidea sp. & & 1.02 & 0.94 & & & & 0.576 & 0.653 & $<0.001$ & $<0.001$ \\
\hline Boccardia syrtis & & 1.83 & 1.65 & 1.18 & 1.74 & 1.52 & 0.060 & 0.039 & $<0.001$ & $<0.001$ \\
\hline Heteromastus filiformis & & 1.11 & 1.81 & 1.24 & 0.93 & 0.75 & 0.160 & 0.023 & $<0.001$ & 0.056 \\
\hline Macomona liliana & 1.92 & 1.82 & 1.34 & 2.00 & 1.94 & 2.10 & $<0.001$ & 0.001 & $<0.001$ & $<0.001$ \\
\hline Nucula hartvigiana & 1.52 & 1.50 & 1.33 & 1.33 & 1.45 & 1.98 & 0.003 & 0.003 & $<0.001$ & $<0.001$ \\
\hline Torridoharpinia hurleyi & 1.00 & 1.26 & 1.23 & 1.55 & 1.12 & 1.05 & $<0.001$ & 0.001 & $<0.001$ & $<0.001$ \\
\hline Colurostylis lemerum & 1.15 & & 1.47 & 1.36 & 1.27 & 1.29 & $<0.001$ & 0.209 & $<0.001$ & $<0.001$ \\
\hline
\end{tabular}

preferences were removed from the analysis. $\mathrm{CV}$ and SD were calculated for each species/site on each sampling occasion and then averaged over the time period and the site averages correlated with sediment mud content (Pearson's R and Speaman's rho). Again a significant positive relationship equates to an increase in variance with increased stress. The mean and variance were calculated for each species/site on sampling occasion. The slope derived for the variance-mean relationship for each species at each site was then assessed for the degree of correlation with stress (sediment mud content), using both Spearman's $\rho$ and Pearson's R.

\section{RESULTS}

Natural Changes in Spatial Variability Over Time (5.5 yrs)

Spatial variability of a species' abundance, as represented by $\mathrm{SD}$ and $\mathrm{CV}$, varied seasonally and across years within

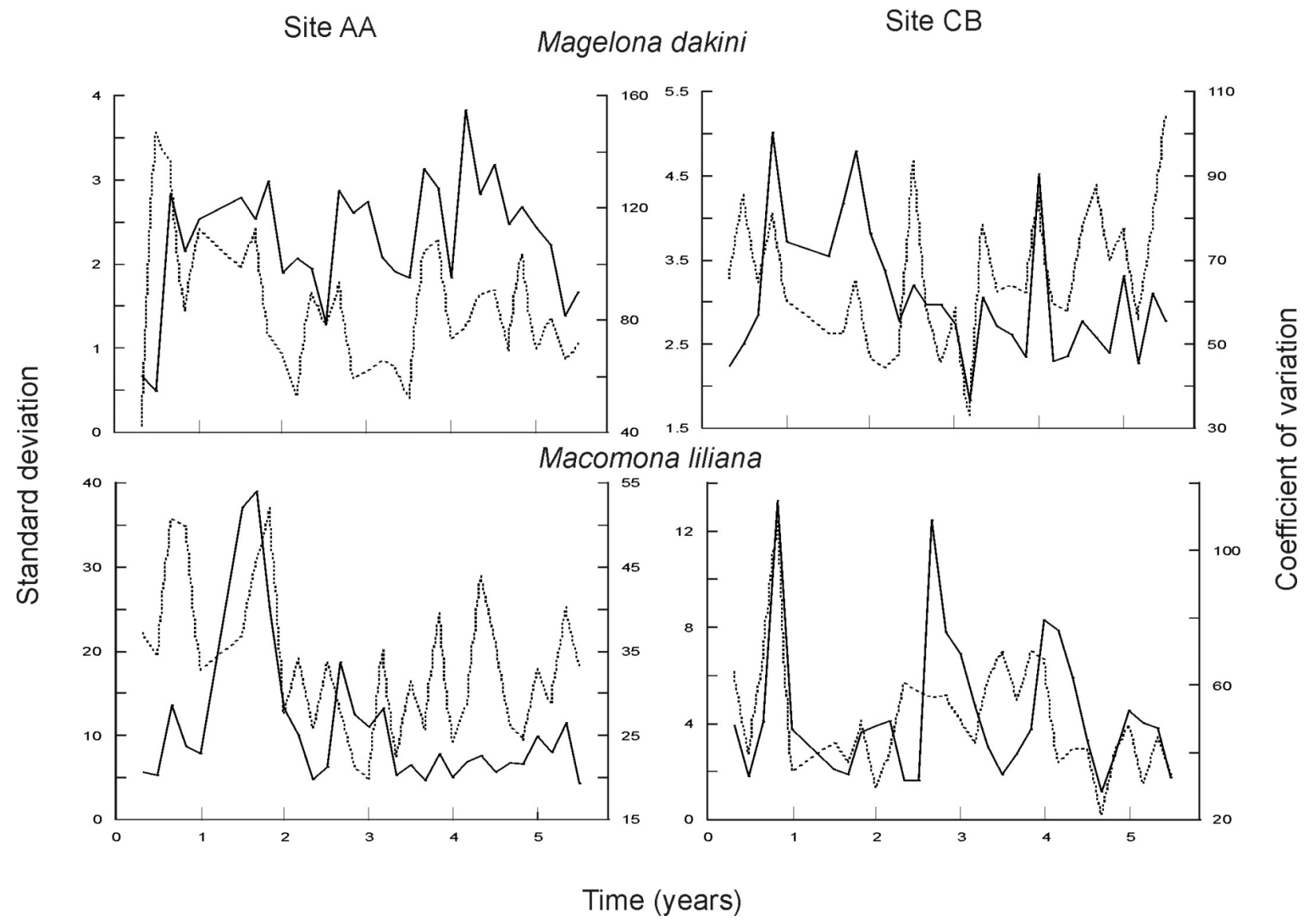

Fig. (2). Two species exhibiting different patterns over time in spatial variation at two sites over a 5.5 year period. Spatial variation is measured as the coefficient of variation (dashed line) and standard deviation of $\log _{\mathrm{e}}(\mathrm{x}+1)$ (solid line). 
Table 2. Results of Tests Carried Out on Common Species before and after the Removal of the Oxidation Ponds. Columns Labelled CV, SD and Mean Contain t-Values with $*=\mathbf{p}-$ Value $<0.05, * *=p-V a l u e<0.01$. Period and Interaction Columns Contain the p-Values for the Results of an ANCOVA Conducted on the Variance-Mean Relationship between the Two Periods. The Significance Level Used for the Interaction Term is 0.15 and Period $1 n=30$, Period $2 n=30$

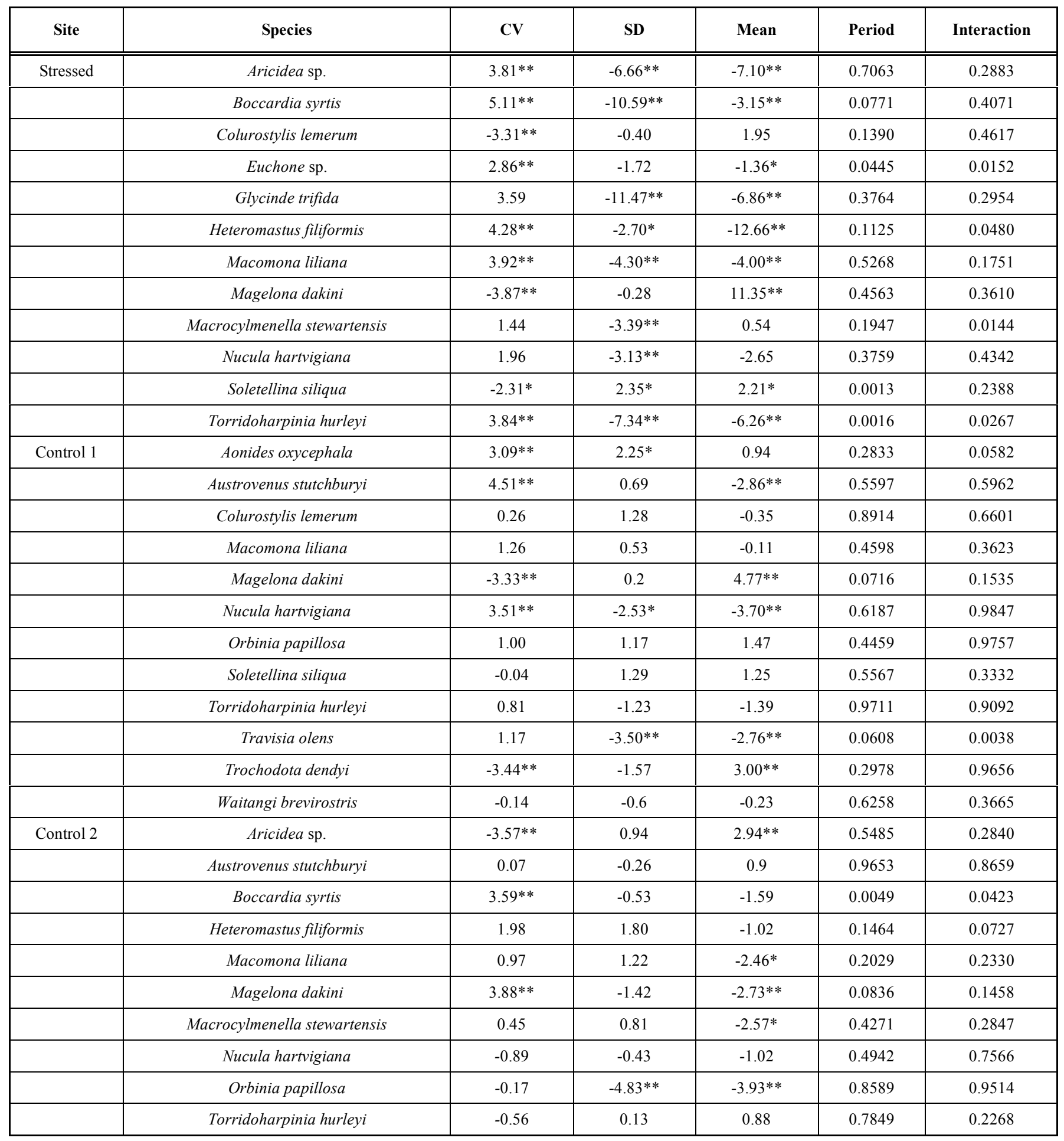

and between sites (Tables $\mathbf{1}$ and 2, Fig. 2) as per hypothesis N1. Generally, CV exhibited more marked seasonality and stronger multi-year cycles than the SD. Peaks and troughs of the two measures were not always consistent. Between the two 5 year periods changes in spatial variability were ob- served for $<30 \%$ of the common species at each of the two long-term monitored sites (Table 2) in contrast to hypothesis N1. More changes were observed for the CV than the SD and generally there were more increases in CV than decreases. Not surprisingly, the degree of variability observed 

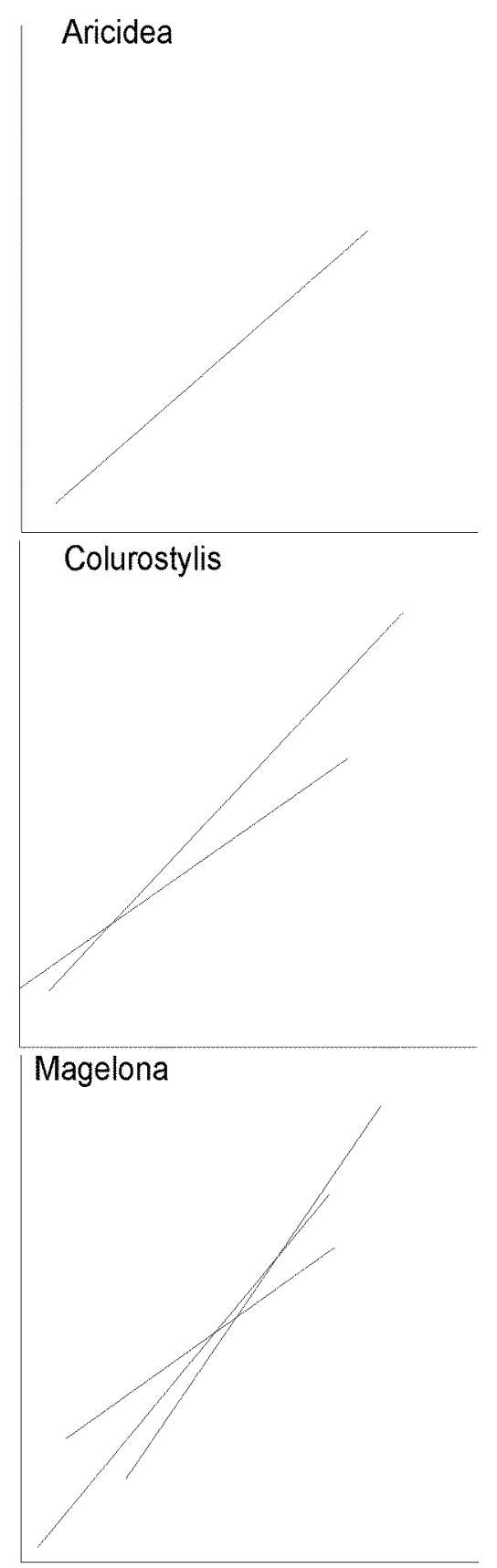
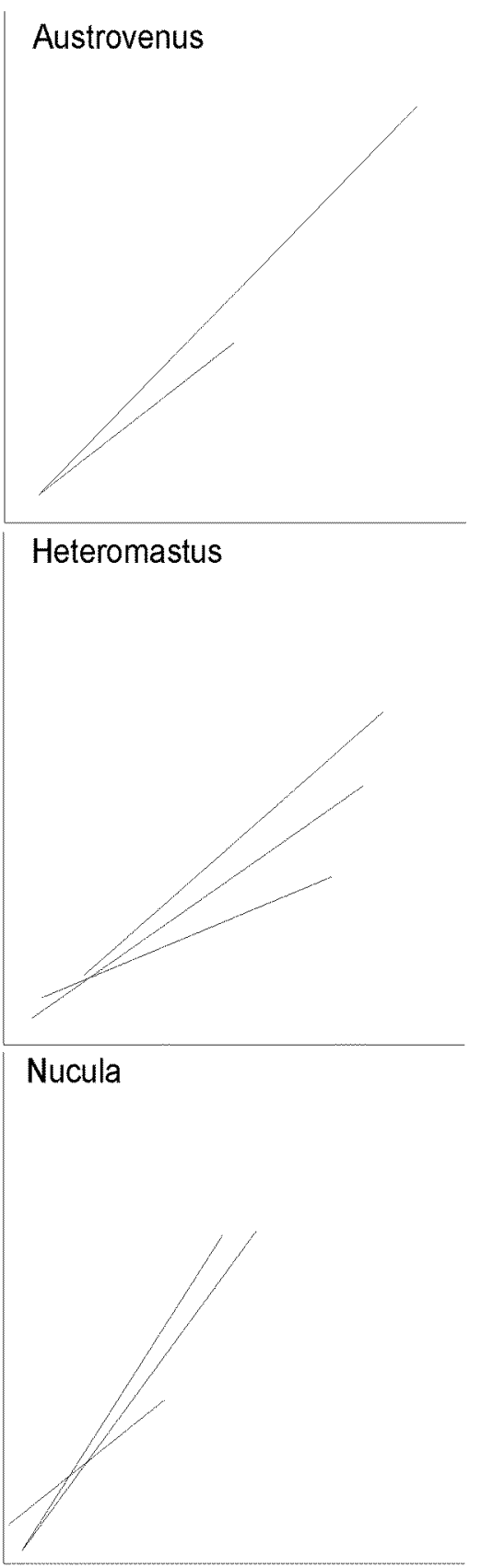

Boccardia

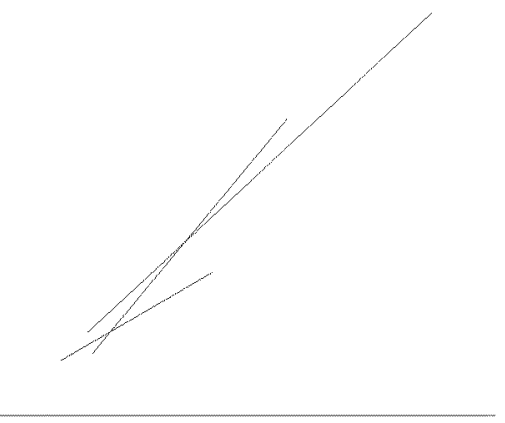

Macomona

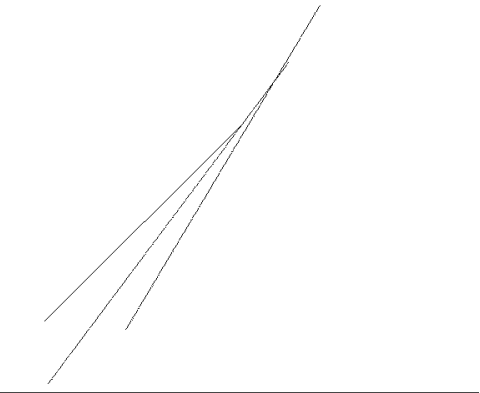

Torridoharpinia

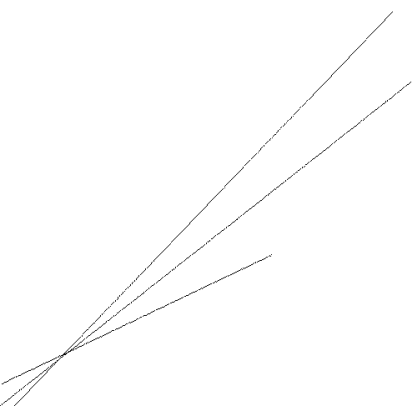

Fig. (3). The natural log variance-mean relationship of all species common at more than one site, showing the range in slopes and intercepts observed at the different sites. Regression lines shown are significantly different to each other (see Table $\mathbf{1}$ for statistics).

for a species was generally not similar across sites (Table 1) as per hypothesis $\mathrm{N} 2$.

The differences observed between sites in patterns of spatial variability are reflected in changes in either the slope or intercept of the site-specific variance-mean relationships over time at all sites (Table 1, Fig. 3), in contrast to hypothesis N3. Slopes were significantly different for 7 of the 9 species abundant across the harbour, emphasising the need for site-specific relationships. Slopes were similar to many others reported in the literature, mainly varying from 1 to 1.7 , however, values approaching 2 were only observed for one bivalve species (Macomona liliana) that is highly mobile as a post-settlement juvenile and values lower than 0.76 were observed for two species of deposit feeding polychaetes (Heteromastus filiformis and Magelona dakini) albeit at only one site each. Five species also showed differences in the intercept between sites.

We predicted that, in the absence of stress, the variancemean relationship of a species at a site would not differ between time periods, despite strong within-year seasonality (N4). This was not always the case and a few significant differences between the two time periods were observed for the two Manukau control sites (Table 2). Changes for 2 of the 12 common species were detected for one site and for 2 of the 10 common species at the other. 
Table 3. Numbers of Species for which Changes were Detected as a Result of Stress that were in Accordance with Hypotheses S1 (Stress Increases CV), S2 (Stress should Increase SD Unless the Mean Abundance Decreases Markedly) and S3 (Stress should Increase the Slope or Intercepts of the Variance-Mean Relationship). Numbers of Decreases in CV in CV, SD and Slopes and Intercepts are also given. Full Results for Individual Species are given in Tables 2, 4 and 5

\begin{tabular}{|c|c|c|c|c|}
\hline & Manukau Stressed & Sediment Experiment 1 & Sediment Experiment 2 & Sediment Mud Gradient \\
\hline \hline \#species tested & 12 & 7 & 11 & 3 \\
\hline S1 supported & 6 & 2 & 2 & 2 \\
\hline S1 not supported & 0 & 1 & 0 & 0 \\
\hline S2 supported & 3 & 0 & 5 & 3 \\
\hline S2 not supported & 5 & 4 & 0 & 4 \\
\hline S3 supported & 0 & 0 & 5 \\
\hline
\end{tabular}

\section{Does Stress Increase Spatial Variability?}

Changes in spatial variability were assessed for both surveys and experiments. For the $\mathrm{CH}$ site in the Manukau, changes between the stressed and non-stressed period were detected in either SD or CV for 8 of the 12 common species (Table 2). This is a significantly higher number of changes than for the control sites ( 3 changes out of 12 or 2 changes out of 10 common species). Omitting changes that occurred at both the stressed site and either of the control sites and changes at the stressed site for species exhibiting increases in abundance, which are considered not to be related to stress, 7 of the 12 common species still exhibited changes in variability between the two periods at the stressed site. However, changes to variability related to stress were not always increases (Table 3) with the hypothesis for $\mathrm{CV}$ being more often supported than that for SD. The CV was more likely to exhibit increases than decreases in response to stress $(6$ increases 0 decreases) than for natural changes (e.g., 3 or 2 increases vs. 2 or 1 decreases at the control sites). Conversely the SD was more likely to exhibit decreases than increases as a result of stress ( 8 decreases $v s .0$ increase) than the natural changes ( 1 or 1 decreases $v s .2$ or 0 increases). This was not always an effect of a marked decrease in mean abundance resulting in a decrease in $\mathrm{SD}$, in particular for two species decreases in SD were detected without any corresponding decreases in mean abundance. Moreover, detection of a change in the CV was not always accompanied by detection of a change in the SD and vica versa.

Along the sediment mud gradient, changes in spatial variability correlated with mud content were observed for all of the species for which previous studies had demonstrated a monotonic relationship with mud (Table 3). Thus these changes could be attributed to the stress of changes in mud content. Again the CV was slightly more likely to exhibit increases rather than decreases and the SD more likely to show decreases (Table 3 ), which again were not always related to decreases in the mean. Again, detection of a change in the $\mathrm{CV}$ was not always accompanied by detection of a change in the SD and vica versa.

In the two sediment addition experiments, fewer changes in spatial variation were detected (Table 3), probably due either to the low degree of replication or the low level of treatment. However the overall patterns were similar, suggesting that the results in the two surveys are general responses of spatial variation to stress. In both experiments, the SDs only showed decreases with stress (Table $\mathbf{3}$ ) and this always occurred without a decrease in mean abundance being detected. The $\mathrm{CV}$ was more likely to exhibit increases with stress ( 2 increases $v s .1$ decrease for experiment 1 , and 3 increases vs. 2 decreases for experiment 2). And finally, once more detection of a change in the $\mathrm{CV}$ was not always accompanied by detection of a change in the SD and vica versa.

\section{Does Stress Increase the Slope or Intercept of the Variance-Mean Relationship}

$\mathrm{CH}$, our stressed site, demonstrated changes between the stressed and unstressed period in the variance-mean relationship for over $45 \%$ of the common species, cf maximum of $20 \%$ for the control sites (Table 3 ). The variance-mean rela-

Table 4. Results of Correlation Analysis for CV, SD, Mean Abundance and the Slope of the Variance-Mean Relationship ( $b_{t}$ ) Against Sediment Mud Content in Mahurangi Harbour for Species Exhibiting Sensitivity to Mud. * $=$ p-Value $<0.05, * *=$ p-Value $<\mathbf{0 . 0 1}$

\begin{tabular}{|c|c|c|c|c|c|}
\hline Species & $\boldsymbol{n}$ & CV & SD & Mean & $\mathbf{b}_{\mathbf{t}}$ \\
\hline \hline Austrovenus stutchburyi & 4 & $-0.97^{* *}$ & 0.50 & -0.50 & $-0.98^{* *}$ \\
\hline Boccardia syrtis & 5 & -0.10 & $-0.93^{*}$ & -0.40 & $-0.90^{*}$ \\
\hline Macomona liliana & 5 & $0.94 *$ & -0.37 & $-0.98^{* *}$ & -0.40 \\
\hline Nicon aestuarensis & 4 & 0.83 & $-0.97^{* *}$ & 0.80 & $0.92^{* *}$ \\
\hline Prionospio aucklandica & 3 & $0.99^{*}$ & $-0.99^{*}$ & -0.84 & $-0.97^{*}$ \\
\hline
\end{tabular}


Table 5. Results of Tests Carried Out on Common Species after a Sediment Addition Experiment at 2 sites with Depths of 0, 1, 3, 5 and $7 \mathrm{~mm}$. Columns Labelled CV, SD and Mean contain t-Values with $*=p$-Value $<0.05, * *=p$-Value $<0.01$. The Interaction Columns Contain the p-Values for the Interaction Term in a GzLM of $\log _{e}\left(\right.$ Variance) Against $\log _{e}$ (Mean) and Depth. $n=5$ for all Taxa. Note the Significance Level Used for the Interaction Term is 0.15

\begin{tabular}{|c|c|c|c|c|c|}
\hline Site & Species & $\mathrm{CV}$ & SD & Mean & Interaction \\
\hline \multirow[t]{5}{*}{ Site 1} & Aonides oxycephala & 0.26 & 0.10 & -0.49 & 0.1172 \\
\hline & Macomona liliana & -0.20 & 0.10 & $-0.90 *$ & 0.8480 \\
\hline & Macrocylmenella stewartensis & 0.34 & $-0.95 *$ & -0.81 & 0.0880 \\
\hline & Prionospio aucklandica & $0.90 *$ & -0.30 & -0.87 & 0.0787 \\
\hline & Orbinia papillosa & $0.92 *$ & -0.24 & $-0.96 * *$ & 0.1921 \\
\hline \multirow[t]{9}{*}{ Site 2} & Austrovenus stutchburyi & -0.71 & -0.57 & -0.72 & 0.5589 \\
\hline & Boccardia syrtis & $0.91 *$ & 0.65 & $-0.90 *$ & 0.6236 \\
\hline & Macomona liliana & $-0.90^{*}$ & $-0.88 *$ & -0.79 & 0.6602 \\
\hline & Macrocylmenella stewartensis & 0.51 & -0.21 & $-0.92 *$ & 0.0258 \\
\hline & Notoacmea helmsi & $0.98 * *$ & -0.57 & $-0.97 * *$ & 0.4036 \\
\hline & Nucula hartvigiana & -0.08 & 0.11 & $-0.99 * *$ & 0.0779 \\
\hline & Paracalliope novaezelandiae & 0.50 & -0.75 & $-0.92 *$ & 0.8015 \\
\hline & Prionospio aucklandica & $0.88 *$ & 0.70 & $-0.99 * *$ & 0.0180 \\
\hline & Scoloplos cylindifera & 0.22 & 0.22 & -0.65 & 0.1931 \\
\hline
\end{tabular}

tionship changed along the sediment mud gradient for 4 of the 5 species predicted to be stressed by changes in sediment mud content, with the slope estimate of the variance-mean relationship significantly correlated with sediment mud content. In particular, positive correlations were observed for the species with a preference for sandy sites and a negative correlation for the species preferring muddy sites. In the two sedimentation experiments, changes to the variance-mean relationship (mainly increases in slope) were detected for 4 to 5 of the common species (i.e., over a third of the species).

Importantly, however, in all studies more changes in spatial variability as a result of stress were detected than were changes in the variance-mean relationship, suggesting that changes to the variance-mean relationship are not a sensitive measure of stress.

\section{DISCUSSION}

Accumulating the results of studies across space (50 $\mathrm{m}$ to $5 \mathrm{~km}$ ) and time scales ( $15 \mathrm{~d}$ to $15 \mathrm{yr}$ ), suggested that the spatial variability of a species changes both between locations and at a location over time, both naturally and in response to stress. Neither the CV nor SD consistently showed increases in response to stress (e.g., Underwood \& Chapman 2004), indeed the SD was more likely to exhibit decreases, even when decreases in mean abundance were not detected. The natural variation in spatial variance between sites resulted in the majority of species exhibiting site-specific variancemean relationships and a few species exhibiting different variance-mean relationships over different time periods. Moreover, there was no consistency in whether the observed variance-mean relationship changed in response to stress. However, one generality did emerge; the aggregated response over of the common species was for an increasing number to exhibit changes in spatial variability in response to the studied stressors.

While we did not find consistent increases in spatial variability with stress, increased spatial variability, especially with no change to mean abundance, indicates increased aggregation. Natural aggregation is affected by species-specific interactions with small-scale environmental spatial variability (Wagner 2003), interactions between species (e.g., Hines et al. 1997, Kilpatrick \& Ives 2003) and between adults and juveniles (e.g., Hewitt et al. 1997). Such interactions are likely to alter the effect of stress on the spatial variability in abundance of a particular species and may also result in location-specific variance-mean relationships (Downing 1986, Certain et al. 2007). Decreases in aggregation are also likely as species change from being core species at a site to being transients (Magurran \& Henderson 2003). Moreover, changes in response to stress may be dependent on the initial spatial distribution. For species already showing aggregated distributions, whether variability increases is likely to de- 
pend on the interaction between the stressor and their behaviour, i.e., does aggregation confer a resistance to the stressor (Briones-Fourzán \& Lozano-Álvarez 2008). Without such interactions, populations aggregated at high density may become regular as the mean abundance decreases (Taylor 1961, Rosewell et al. 1990)

For two common species (Aricidea sp. and Colurostylis lemerum), we observed a variance-mean relationship that was not location-specific. Relationships between the variance and mean which are not location-specific suggest the species forms a meta population encompassing the areas sampled and that changes within this metapopulation dominate the spatial responses of this species. Importantly, neither of these two species demonstrated a change in the variancemean ratio in response to stress, despite changes in both spatial variability and mean abundances. Neither did they exhibit natural temporal changes in the relationship. For such species, the response of population dynamics to environmental changes at sites may be predictable by the relative slopes of the spatial and temporal variance-mean relationships.

Conversely, half of the common species that did show location-specific variance-mean relationships also exhibited temporal changes to this relationship at sites that did not appear related to an anthropogenic stressor (see also McArdle $\&$ Anderson 2004). While the slopes of variance-mean relationships have been proposed to approximate 2 for populations with constant environmental variability and carrying capacity, many populations do not exhibit this (Kilpatrick \& Ives 2003). Differences to the slope can be a result of different habitat resources (Krasnov et al. 2006), however decreases in slope have been associated with increasing community diversity (Krasnov et al. 2006), carrying capacity (Keeling 2000) and scale (Keeling 2000). Our results suggest that location-specific variance-mean relationships may also be transient, reflecting interactions between local resource patterns and recruitment. This extends the implications of the combined variance-abundance-occupancy models created by He \& Gaston (2003) whose work suggested that differences between variance-abundance relationships may be caused by different occupancy rates. Such spatially and temporally specific relationships have implications for the design of experimental studies (replication and magnitude of effects detected) and the analysis of time series. Certainly they demonstrate that changes in the variance-mean relationship per se may not be used as an indicator of stress.

Importantly, our study does demonstrate that changes to variability do occur as a result of stress. That variability does not always increase implies that changes to variability in abundance will not be useful as an assessment of stress unless this is associated with a high degree of natural history knowledge of the species. However, at the community level, our results hint at a more consistent pattern emerging, as the number of common species demonstrating changes to their spatial variability, beyond that which occurs naturally, did increase markedly with stress. Changes to spatial variability of an increasing numbers of common species may affect community stability, particularly where self-organised heterogeneity occurs (Rierkerk et al. 2004). Such work suggests that it is important to establish whether changes in spatial variability that are inconsistent in direction between species within a community destabilise community interactions, leading to decreased resilience and the potential for regime shifts, or whether they smooth out tensions between species, increasing resilience (e.g., van Nes \& Scheffer 2005). Work by Kilpatrick \& Ives (2003) demonstrating that negative species interactions can result in decreases in the slope of the variance-mean relationship for most species, suggests that increasing resilience is more likely to be a result.

In conclusion, our findings demonstrate a complex relationship between spatial variability and mean abundances for species at a variety of spatial and temporal scales that do not represent a simple power law operating at broad-scales. This complex relationship also results in no simple relationship between stress and measures of spatial variability at the population level. However, at a community level, increases in the number of common species exhibiting changes in spatial variability did seem to be associated with stress, over a variety of spatial and temporal scales. Therefore, we suggest that it is change per se that is the important response to stress. This has important implications for our ability to make predictions about responses to stressors, suggesting that indirect effects, small-scale site-specific biological responses and feedbacks between variability of the stressor and spatial variability of abundances will be important factors.

\section{ACKNOWLEDGEMENTS}

This work was supported by FRST C01X0307. Most of the long-term monitoring data was supplied by the Auckland Regional Council.

\section{REFERENCES}

Briones-Fourzan, P \& Lozano-Álvarez, E (2008) Coexistence of congeneric spiny lobsters on coral reefs: differences in conspecific aggregation patterns and their potential antipredator benefits. Coral Reefs, 27, 275-87.

Callaghan, A \& Holloway, GJ (1999) The relationship between environmental stress and variance. Ecological Applications, 9, 456-62.

Certain, G, Belliger, E, Planque, B \& Bretagnolle, V (2007) Characterising the temporal variability of the spatial distribution of animals: an application to seabirds at sea. Ecography, 30, 695-708.

Crooks, KR \& Sanjayan, M (2006) Connectivity conservation, Cambridge University Press, Cambridge.

Downing, JA (1979) Aggregation, transformation, and the design of benthos sampling programs. Journal of the Fisheries Research Board of Canada, 36, 1454-63.

Downing, JA (1986) Spatial heterogeneity: evolved behaviour or mathematical artefact? Nature, 323, 255-7.

Elliott, JM (2005) Day-night changes in the spatial distribution and habitat preferences of freshwater shrimps, Gammarus pulex, in a stony stream. Freshwater Biology, 50, 552-66.

Forbes, VE, Moller, V \& Depledge, MH (1995) Intrapopulation variability in sublethal response to heavy metal stress in sexual and asexual gastropod populations. Functional Ecology, 9, 477-84.

Gaston, KJ \& McArdle, BH (1994) The temporal variability of animal abundances: measures, methods and patterns. Philosophical Transactions: Biological Sciences, 345, 335-58.

He, F \& Gaston, KJ (2003) Occupancy, spatial variance and the abundance of species. American Naturalist, 162, 366-75.

Heath, JP (2006) Quantifying temporal variability in population abundances. Oikos, 115, 573-81.

Hewitt, JE, Legendre, P, McArdle, BH, Thrush, SF, Bellehumeur, C \& Lawrie, SM (1997) Identifying relationships between adult and juvenile bivalves at different spatial scales. Journal of Experimental Marine Biology and Ecology, 216, 77-98.

Hewitt, JE \& Thrush, SF (2007) Effective long-term monitoring using spatially and temporally nested sampling. Environmental monitoring and assessment, 133, 295-307. 
Hines, AH, Whitlatch, RB, Thrush, SF, Hewitt, JE, Cummings, VJ, Dayton, PK \& Legendre, P (1997) Nonlinear foraging response of a large marine predator to benthic prey: eagle ray pits and bivalves in a New Zealand sandflat. Journal of Experimental Marine Biology and Ecology, 216, 211-28.

Inchausti, P \& Halley, J (2002) The long-term temporal variability and spectral colour of animal populations. Evolutionary Ecology Research, 4, 1033-48.

Keeling, MJ (2000) Simple stochastic models and their power-law type behaviour. Theoretical Population Biology, 58, 21-31.

Kilpatrick, AM \& Ives, RA (2003) Species interactions can explain Taylor's power law for ecological time series. Nature, 422, 65-8.

Krasnov, BR, Stanko, M, Miklisova, D \& Morand, S (2006) Host specificity, parasite community size and the relation between abundance and its variance. Evolutionary Ecology, 20, 75-91.

Legendre, P (1993) Spatial autocorrelation: trouble or new paradigm? Ecology, 74, 1659-73.

Lewontin, RC (1966) On the measurement of relative variability. Systematics Zoology, 15, 141-2.

Lohrer, AM, Thrush, SF, Hewitt, JE, Berkenbusch, K, Ahrens, M \& Cummings, VJ (2004) Terrestrially derived sediment: response of marine macrobenthic communities to thin terrigenous deposits. Marine Ecology Progress Series, 273, 121-38.

Magurran, AE \& Henderson, PA (2003) Explaining the excess of rare species in natural species abundance distributions. Nature, 422, 714-6.

McArdle, BH \& Gaston, KJ (1993) The temporal variability of populations. Oikos, 67, 187-91.

McArdle, BH \& Anderson, MJ (2004) Variance heterogeneity, transformations and models of species abundances: a cautionary tale. Canadian Journal of Fisheries and Aquatic Sciences, 61, 12941302.

Rierkerk, MS, Dekker, SC, de Ruiter, PC \& van de Koppel, J (2004) Selforganized patchiness and catestrophic shifts in ecosystems. Science, 305, 1926-9.

Rosewell, J, Shorrocks, B \& Edwards, K (1990) Competition on a divided and emphemeral resource: testing the assumptions. 1 Aggregation. Journal of Animal Ecology, 59, 977-1001.

Simkiss, K \& Mason, AZ (1984) Cellular responses of molluscan tissues to environmental metals. Marine Environmental Research, 14, 10318.

Taylor, LR (1961) Aggregation, variance, and the mean. Nature, 189, 732-5.

Taylor, LR (1971) Aggregation as a species characteristic. Statistical Ecology, 1, 357-77.

Taylor, LR, Woiwod, IP \& Perry, JN (1980) Variance and the large scale spatial stability of aphids, moths and birds. Journal of Animal Ecology, 49, 831-54.

Taylor, LR (1984) Assessment and interpreting the spatial distributions of insect populations. Annual Review of Entomology, 29, 321-57.

Taylor, LR, Perry, JN, Woiwod, IP \& Taylor, RAJ (1988) Specificity of the spatial power-law exponent in ecology and agriculture. Nature, London, 332, 7721-2.
Thrush, SF, Hewitt, JE \& Pridmore, RD (1989) Patterns in the spatial arrangement of polychaetes and bivalves in intertidal sandflats. Marine Biology, 102, 529-36.

Thrush, SF, Pridmore, RD, Hewitt, JE \& Cummings, VJ (1992) Adult infauna as facilitators of colonization on intertidal sandflats. Journal of Experimental Marine Biology and Ecology, 159, 253-65.

Thrush, SF, Pridmore, RD \& Hewitt, JE (1994) Impacts on soft-sediment macrofauna: the effects of spatial variation on temporal trends. Ecological Applications, 4, 31-41.

Thrush, SF, Hewitt, JE, Pridmore, RD \& Cummings, VJ (1996) Adult/juvenile interactions of infaunal bivalves: contrasting outcomes in different habitats. Marine Ecology Progress Series, 132, 83-92.

Thrush, SF, Hewitt, JE, Norkko, A, Nicholls, PE, Funnell, GA \& Ellis, JI (2003) Habitat change in estuaries: predicting broad-scale responses of intertidal macrofauna. Marine Ecology Progress Series, $263,113-25$.

Thrush, SF, Hewitt, JE, Cummings, VJ, Ellis, JI, Hatton, C, Lohrer, A \& Norkko, A (2004) Muddy waters: elevating sediment input to coastal and estuarine habitats. Frontiers in Ecology and Environment, 2, 299-306.

Thrush, SF, Hewitt, JE, Gibb, M, Lundquist, C \& Norkko, A (2006) Functional role of large organisms in intertidal communities: community effects and ecosystem function. Ecosystems, 9, 102940.

Tilman, D, May, RM, Lehman, CL \& Nowak, MA (1994) Habitat destruction and the extinction debt. Nature, 371, 65-6.

Turner, SJ, Thrush, SF, Pridmore, RD, Hewitt, JE, Cummings, VJ \& Maskery, M (1995) Are soft-sediment communities stable? An example from a windy harbour. Marine Ecology Progress Series, 120, 219-30.

Underwood, AJ \& Chapman, MG (2004) Variation in abundances of intertidal populations: consequences of extremities of environment. Hydrobiologia, 426, 25-36.

van Nes, EH \& Scheffer, M (2005) Implications of spatial heterogeneity for catastrophic regime shifts in ecosystems. Ecology, 86, 1797-1807.

Wagner, HH (2003) Spatial covariance in plant communities: integrating ordination, geostatistics and variance testing. Ecology, 84, 1045-57.

Warwick, RM \& Clarke, KR (1993) Increased variability as a symptom of stress in marine communities. Journal of Experimental Marine Biology and Ecology, 172, 215-26.

Whitlatch, RB, Hines, AH, Thrush, SF, Hewitt, JE \& Cummings, VJ (1997) Benthic faunal responses to variations in patch density and patch size of a suspension-feeding bivalve inhabiting a New Zealand intertidal sandflat. Journal of Experimental Marine Biology and Ecology, 216, 171-90.

Wilcock, RJ \& Martin, ML (2003) Baseline water quality survey of the Auckland region. Annual report January - December 2002, NWA, Hamilton.

Received: January 09, 2009

Revised: February 12, 2009

Accepted: February 24, 2009

(C) Hewitt and Thrush; Licensee Bentham Open.

This is an open access article licensed under the terms of the Creative Commons Attribution Non-Commercial License (http://creativecommons.org/licenses/by$\mathrm{nc} / 3.0 /$ ), which permits unrestricted, non-commercial use, distribution \& reproduction in any medium, provided the work is properly cited. 